\title{
The Effect of the Comprehensive Midwifery Care Model with the One Student One Client (OSOC) Approach to Birth Outcomes in North Aceh Regency
}

\author{
Rildayani $^{1}$, Nurjannah ${ }^{2}$, Irwan Saputra ${ }^{3}$, Cut Meurah Yeni ${ }^{4}$, Said Usman ${ }^{5}$ \\ 1,2,3,4,5 Magister Program of Public Health, Faculty of Medicine, Universitas Syiah Kuala, Indonesia \\ rildadadi@gmail.com,nurjannah_dr@unsyiah.ac.id,iwanbulba@unsyiah.ac.id cutyeni65@gmail.com, \\ saidusman@unsyiah.ac.id
}

\section{Abstract}

Maternal and Newborn Health is a priority as the main indicator in health. During the pregnancy period until the puerperium it is estimated that as many as $15 \%$ can experience life-threatening complications of the mother and baby. However, this death is considered to be prevented through the provision of comprehensive care that can be done with the One Student One Client (OSOC) approach, which is an activity that exists between low-risk pregnant women and midwife students during pregnancy up to 6 weeks post delivery. Objective: This study aims to assess the relationship of comprehensive midwifery care with the One Student One Client (OSOC) approach to birth outcomes (gestational age at delivery, prolonged labor and asphyxia) Method: This study is a retrospective cohort study, using secondary data from medical record documentation Results: Comprehensive midwifery care with the OSOC approach was associated with the occurrence of prolonged labor $p$ value 0.046 (RR 95\% CI; 3.2 (1.08-9.74), asphyxia with $p$ value 0.037 (RR 95\% CI; 2.57 1.12-6.50) Conclusion: The OSOC method can be used in comprehensive midwifery care for all mothers and babies from pregnancy up to 6 weeks post delivery in an effort to improve birth outcomes.
Keywords

comprehensive midwifery care; OSOC, birth outcomes

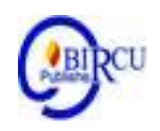

\section{Introduction}

Health is a very important element of the quality of life in national development. The national health system has established that the goal of health development is to increase awareness, willingness, and ability to live healthy for everyone so that a high degree of public health can be realized - high human resources, as an investment for socially and economically productive development Health Law No. 36 of 2009. (Hasibuan, 2020).

Maternal and Newborn Health is important to be improved and as a leading indicator in health (Madan et al., 2017). The high number of maternal deaths in several regions of the world, shows the gap in access to health services between developed and poor countries. Maternal deaths occur as much as $99 \%$ in developing countries and more than half of these deaths occur in Africa and sub-Saharan, and nearly one third occur in the South Asian continent. More than half of maternal deaths occur in environments with poverty and humanitarian problems (WHO, 2018). Judging from the difference in the magnitude of death between developed and developing countries, the risk of lifetime maternal mortality in developed countries is 1: 3300, while deaths in developing countries are 1:41 (United Nations Children's Fund, 2017). 
In Indonesia, one of the programs implemented by the government to reduce maternal and infant mortality is the placement of midwives in remote areas, with the aim that mothers and babies can access health services, in this condition for continuity of care activities have not been implemented effectively (Yuningsih, 2016; UNICEF, 2017). During the period of pregnancy until the puerperium, as many as $15 \%$ are estimated to experience complications, this can threaten the lives of mothers, but almost all maternal deaths are considered preventable (Bappeda, 2016; UNICEF, 2017). Prevention can be done by finding early complications or problems through increasing access to services to women by providing quality care starting from pregnancy, childbirth, and the puerperium (WHO, 2017). Quality care and continuing is done by midwives starting from pregnancy care, up to the use of postdelivery Family Planning. As many as $83 \%$ of all maternal and infant deaths can be prevented through ongoing midwifery care and family planning (Homer et al., 2014). Antenatal Care (ANC) is considered a globally recommended strategy for all women in the world to prevent neonatal death (Arunda et al., 2017). In many countries, asphyxia is one of the causes of neonatal death besides premature and infection, but all these risks can be reduced and prevented by continuous ANC examination (Arunda et al., 2017). Prenatal care is expected to influence birth outcomes and can prevent birth-related complications such as asphyxia (Nimi et al., 2016). Research has shown that newborns from mothers who receive support during labor have a higher Apgar Score (Hodnett, 2000).

The role of midwives has improved since maternal health and low birth weight have become the focus of targets for the MDGs in 2015 (WHO, 2013). Women who are treated by midwives in a comprehensive manner are less likely to experience losses such as premature birth, and prolonged labor (Chapman, 2016). The comprehensive service model cared for by midwives is special professional care and is responsible for women during low-risk pregnancies in planning, providing care, and referring to other appropriate professionals, with the aim of providing care by building partnerships between mothers and midwives (Sandall et al., 2016).

ANC is also one of the efforts that can be done to reduce complications that can arise during labor (UNICEF, WHO, 2003). The continuous care model led by midwives aims to support a woman during pregnancy, childbirth, and after birth. The role of the midwife is also as a facilitator of healthy pregnancy and quality care (WHO, 2018). According to (Chapman, 2016; Shimoda et al., 2015), it has been well documented that many complications can be avoided during skilled and comprehensive care. All possible complications can occur by monitoring the progress of maternal labor, fetal well-being, timely medical interventions, reducing prolong deliveries, and timely referrals (Shimoda et al., 2015).

In order to reduce maternal mortality, the province of Central Java has established a mentoring program called One Student One Client (OSOC). Through this program, there has been a decrease in maternal and infant mortality since 2012-2015 (Central Java Provincial Government, 2018). In Aceh province, the community uses the services of midwives as birth and baby care assistance and some midwifery education in North Aceh has been undergoing OSOC activities through clinical practice since 2015. This activity is a partnership between low-risk pregnant women and a midwife student conducted at Health Academy (Akkes) in North Aceh Regency, carried out starting from pregnancy up to 6 weeks post-delivery. This activity is one of clinical practice learning with the aim of supporting intra-uterine maternal and fetal well-being, detecting risk discoveries, also conducting home visits up to 6 weeks after delivery, OSOC is carried out through mentoring one student with one mother during care (Reference to the Implementation of Comprehensive Student Practices D III Midwifery Government of North Aceh Regency, 2019). 
In the area of North Aceh Regency, deaths each year have not shown a significant decrease, North Aceh district contributes the highest mortality rate in Aceh (Aceh Health Office, 2017). The large number of midwives placed in North Aceh District has not demonstrated success in reducing maternal mortality (Aceh Health Office, 2017). Based on the above background, researchers are interested in conducting research to investigate the relationship of comprehensive midwifery care with the OSOC approach to birth outcomes in North Aceh District.

\section{Research Methods}

This research is a quantitative study with a retrospective cohort design. A total of 300 pregnant women were included in this study, with 150 pregnant women accompanied by students ranging from three trimester to six weeks post delivery (OSOC + midwife clinic), and 150 pregnant women not accompanied by students in midwife clinic in the North Aceh district. The processed data was obtained from partograph sheets and SOAP documentation (Subjective, Objective, Assessment, and Planning) in medical records recorded by students. Birth outcomes included gestational age (term / preterm), prolonged labor and asphyxia status. Statistical analysis was performed using the Chi-Square test with a significance level of $\mathrm{p}<0.05$ and relative risk analysis. The software used in data processing is IBM SPSS 25 .

\section{Result and Discussion}

The average age of mothers in OSOC assistance and mothers in midwife clinic was 28 years. The minimum age of the mother is 18 years and the maximum age of the mother is 47 years. The average gravida is 2.37 for OSOC and 2.56 for mother in midwife clinic, with a maximum gavida of 9 . Work status as a housewife is the most work for mothers. Cases of asphyxia, prolonged labor, are more common in births that are not accompanied by OSOC (Table 1).

Table 1. Frequency distribution of respondent characteristics in North Aceh Regency in 2019

\begin{tabular}{|c|c|c|c|c|c|c|}
\hline \multirow{3}{*}{ Characteristics } & \multicolumn{4}{|c|}{ Accompaniment } & \multirow{2}{*}{\multicolumn{2}{|c|}{ Total }} \\
\hline & \multicolumn{2}{|c|}{ OSOC } & \multicolumn{2}{|c|}{$\begin{array}{c}\text { Non OSOC } \\
\text { (midwife clinic only) }\end{array}$} & & \\
\hline & $\mathbf{n}$ & $\%$ & $\mathbf{n}$ & $\%$ & $\mathbf{n}$ & $\%$ \\
\hline \multicolumn{7}{|l|}{ Mother's age } \\
\hline - Low risk & 136 & 52.31 & 124 & 47.69 & 260 & 100 \\
\hline - $\quad$ High risk & 14 & 35.00 & 26 & 65.00 & 40 & 100 \\
\hline \multicolumn{7}{|l|}{ Gravida } \\
\hline - $\quad$ Primigravida & 28 & 34.57 & 53 & 65.43 & 81 & 100 \\
\hline Multigravida & 115 & 57.50 & 85 & 42.50 & 200 & 100 \\
\hline Grandemultigravida & 7 & 36.84 & 12 & 63.16 & 19 & 100 \\
\hline \multicolumn{7}{|l|}{ Profession } \\
\hline - $\quad$ Housewife & 145 & 49.66 & 147 & 50.34 & 292 & 100 \\
\hline Civillian Servant & 4 & 57.14 & 3 & 42.86 & 7 & 100 \\
\hline Entrepreneur & 1 & 100.00 & 0 & 0.00 & 1 & 100 \\
\hline \multicolumn{7}{|l|}{ Age of Pregnancy } \\
\hline Aterm & 150 & 50.17 & 149 & 49.83 & 299 & 100 \\
\hline - $\quad$ Preterm & 0 & 0.00 & 1 & 100.00 & 1 & 100 \\
\hline \multicolumn{7}{|l|}{ Prolonged delivery } \\
\hline Yes & 4 & 23.52 & 13 & 76.47 & 17 & 100 \\
\hline
\end{tabular}




\begin{tabular}{|c|c|c|c|c|c|c|}
\hline \multirow{2}{*}{\multicolumn{7}{|c|}{$\begin{array}{l}\text { No } \\
\text { Asfiksia }\end{array}$}} \\
\hline & & & & & & \\
\hline - $\quad$ Yes & 7 & 28.00 & 18 & 72.00 & 25 & 100 \\
\hline No & 143 & 52.00 & 132 & 48.00 & 275 & 100 \\
\hline
\end{tabular}

Chi-Square test results (table 2) show that OSOC assistance at midwife clinic has a significant relationship to the incidence of asphyxia $(\mathrm{p}=0.037 ; \mathrm{RR}=2.57)$, prolonged labor $(\mathrm{p}=0.046 ; \mathrm{RR}=3.2)$. This shows that mothers without OSOC assistance was 2.57 more likely to experience asphyxia than mothers who were accompanied by OSOC at the midwife clinic.

Table 2. Results of Comprehensive Midwifery Analysis with the OSOC Approach to

Pregnancy at delivery

Pregnancy at Childbirth

\begin{tabular}{lccccc}
\cline { 2 - 5 } \multicolumn{1}{c}{ Approach } & \multicolumn{2}{c}{ Preterm } & \multicolumn{2}{c}{ Aterm } & \multirow{2}{*}{ P value } \\
\cline { 2 - 5 } & $\mathbf{n}$ & $\mathbf{\%}$ & $\mathbf{n}$ & $\mathbf{\%}$ & \\
\hline Non OSOC & 1 & 0.7 & 149 & 99.3 & 1,000 \\
\hline OSOC & 0 & 0.0 & 150 & 100.0 & \\
\hline
\end{tabular}

Table 3. Results of Comprehensive Midwifery Analysis with the OSOC Approach to Old Labor

\begin{tabular}{|c|c|c|c|c|c|c|c|}
\hline \multirow{3}{*}{ Approach } & \multicolumn{4}{|c|}{ Prolonged delivery } & \multirow{3}{*}{ Total } & \multirow{3}{*}{ P value } & \multirow{3}{*}{$\begin{array}{c}\text { RR } \\
(\mathbf{9 5 \%} \mathrm{CI})\end{array}$} \\
\hline & \multicolumn{2}{|c|}{ Yes } & \multicolumn{2}{|c|}{ No } & & & \\
\hline & $\mathrm{n}$ & $\%$ & $\mathrm{n}$ & $\%$ & & & \\
\hline Non OSOC & 13 & 76.47 & 146 & 57.70 & 150 & & \\
\hline OSOC & 4 & 23.52 & 137 & 48.40 & 150 & 0.046 & $3,2(1.08-9.74)$ \\
\hline
\end{tabular}

Table 4. Results of Comprehensive Midwifery Analysis with the OSOC Approach to Asphyxia

\begin{tabular}{|c|c|c|c|c|c|c|c|}
\hline \multirow{3}{*}{ Approach } & \multicolumn{4}{|c|}{ Asphixia } & \multirow{3}{*}{ Total } & \multirow{3}{*}{$\begin{array}{c}\mathrm{P} \\
\text { value }\end{array}$} & \multirow{3}{*}{$\begin{array}{c}\mathbf{R R} \\
(95 \% \mathrm{CI})\end{array}$} \\
\hline & \multicolumn{2}{|c|}{ Yes } & \multicolumn{2}{|c|}{ No } & & & \\
\hline & $\mathbf{n}$ & $\%$ & $\mathrm{n}$ & $\%$ & & & \\
\hline Non OSOC & 18 & 12.0 & 132 & 88.0 & 150 & 0,037 & $2.57(1.12-6.50)$ \\
\hline OSOC & 7 & 4.7 & 143 & 95.3 & 150 & & \\
\hline
\end{tabular}

Assistance to the mother during full labor gives a positive impact on the duration of active labor during the first stage (Sydsjo et al., 2015). Besides this, full assistance can also have a good effect on birth outcomes (Sydsjo et al., 2015). The results of the study by Sydsjo et al. (2015) showed that women with delivery assistance had shorter duration of labor compared to women who did not get assistance with $\mathrm{p}$ values 0.047 . Research conducted by Sehatie et al., (2014) indicated that 150 women who were comprehensively accompanied during labor also had a good effect on birth outcomes such as reduced oxytocin use during the first stage $(\mathrm{p}=0.001)$ and lower perineal laceration $(\mathrm{p}=0.001)$. This shows that in addition to shortening the first phase, mentoring also reduces some of the unnecessary interventions during labor. The constant presence of midwives during the labor phase strengthens the ability of a woman's body to produce analgesic / endorphin which can provide comfort and happiness / euphoria. This condition causes good stimulation and can reduce labor induction, making shorter duration of labor so that labor is not obstructed (Sehatie et al., 2014). The results of this study also support previous research that there is an effect of comprehensive midwifery care with the OSOC approach to the incidence of prolonged labor. 
ACOG, (2017) recommends that when a woman enters the labor phase with the fetus in good condition, the woman is still observed both in terms of pain that is felt, even fatigue that can cause complications during the latent phase until active. In this case, education in the form of education, and good moral support, oral hydration, position, and pain reduction techniques such as massage can reduce the labour pain. Other evidence also shows the emotional support of one midwife with one mother continuously given by a person such as a midwife is associated with better outcomes in women (ACOG, 2017).

The term birth asphyxia is used to indicate a baby cannot breathe spontaneously immediately after birth (Lee et al., 2011). According to WHO (2011) the majority of all neonatal deaths as much as $75 \%$ occur in the first week of birth, around 1 million newborns die due to birth complications, one of which is asphyxia. The neonatal period is an important determinant for subsequent infant survival (Mukhtar Yola et al., 2018). The highest number of deaths during this neonatal period occurs in developing countries with low resources, and the main cause of these deaths is due to asphyxia of birth (Mukhtar Yola et al., 2018). A study conducted by Arunda et al., (2017) which states that asphyxia is a cause of death that can occur in neonates other than premature and infection, but this can be prevented with effective comprehensive care. Comprehensive and skilled obstetric care can minimize the number of infant deaths due to asphyxia (Lee et al., 2011). Assistance carried out through OSOC continuously shows good birth outcomes, namely babies not born with asphyxia after birth. This is in line with research conducted by Lee et al. (2011) which proves that midwives who continually accompany the mother during labor can reduce intrapartum-related events in infants associated with hypoxic injury (birth asphyxia).

Gillam Krakauer and Gowen Jr., (2019) mentioned the condition of birth asphyxia can be minimized by reducing the morbidity due to asphyxia which is done by drying the baby immediately after birth to keep it warm and body temperature maintained (the baby does not experience hypothermia). On the other hand, maternal non-compliance in ANC visits is also associated with asphyxia (Arunda et al., 2017). Other efforts that can be made to reduce morbidity due to asphyxia are timely referral and immediate low birth wight treatment, including drying the baby's body after birth (Lawn et al., 2011).

Other studies have shown that care during ANC can influence the incidence of perinatal asphyxia (Gane et al., 2013). In this study explained that maternal ANC visits less than 3 times during pregnancy have a higher risk for the incidence of asphyxia, with OR $(3,073)$, and p value 0.01 (Gane et al., 2013). In this study the incidence of birth asphyxia occurred in mothers in No OSOC group, out of 53 primiparous mothers (65.4\%), 18 mothers $(72 \%)$ babies were born with asphyxia, whereas in mothers with OSOC assistance asphyxia births were only 7 births ( 28\%). Berhe et al., (2019) in his study found that in addition to comprehensive care provided, maternal gravida can also contribute to asphyxia, especially in mothers with primiparous with AOR 5.5 (95\% CI: 2.5, 12.3).

The problem of infant death due to asphyxia is associated with continuity of maternal health which tends to be not good (WHO, 2011). Maternal care before birth is considered effective enough to reduce morbidity due to asphyxia, this effective care treatment refers to antenatal care for mothers and obstetric care that is able to avoid asphyxia as early as possible (WHO, 2011).

\section{Conclusion}

Comprehensive midwifery care with the OSOC approach has a relationship to better birth outcomes. Thus, the health department and midwives can apply comprehensive midwifery care to all mothers from pregnancy up to 6 weeks post delivery. 


\section{References}

Arunda, M., Emmelin, A., Asamoah, B.O., (2017). Effectiveness of antenatal care services in reducing neonatal mortality in Kenya: analysis of national survey data. Glob. Health Action 10, 1328796. https://doi.org/10.1080/16549716.2017.1328796

Baghiani Moghadam, M.H., Baghianimoghadam, B., Ardian, N., Alizadeh, E.(2015). Risk factors of low birth weight and effect of them on growth pattern of children up to sixth months of life: A cross-sectional study. J. Educ. Health Promot. 4, 40. https://doi.org/10.4103/2277-9531.157226

Bappeda, (2016). Kajian Faktor Risiko Kematian Ibu Dan Bayi Tahun 2016.

Chapman, S. (2016). Midwife-led continuity models versus other models of care: review and reflections [WWW Document]. Evidently Cochrane. URL https://www.evidentlycochrane.net/midwife-led-care/ (accessed 4.17.19).

Dinas Kesehatan Aceh, T.(2017). Profil kesehatan aceh tahun 2017172.

Hasibuan, S.,M. (2020). Relationship of Family Income and Family Support with Maternal Reference in Pregnant Women in Pantai Cermin BEmONC, Langkat District, 2019. Budapest International Research and Critics Institute-Journal (BIRCI-Journal). P. 486493.

Hodnett, E.D. (2000). Caregiver support for women during childbirth. Cochrane Database Syst. Rev. CD 000199. https://doi.org/10.1002/14651858.CD000199

Homer, C.S.E., Friberg, I.K., Dias, M.A.B., Hoope-Bender, P. ten, Sandall, J., Speciale, A.M., Bartlett, L.A. (2014). The projected effect of scaling up midwifery. The Lancet 384, 1146-1157. https://doi.org/10.1016/S0140-6736(14)60790-X

Khanal, V., Scott, J.A., Lee, A.H., Karkee, R., Binns, C.W. (2015). Factors associated with Early Initiation of Breastfeeding in Western Nepal. Int. J. Environ. Res. Public. Health 12, 9562-9574. https://doi.org/10.3390/ijerph120809562

Madaj, B., Smith, H., Mathai, M., Roos, N., van den Broek, N. (2017). Developing global indicators for quality of maternal and newborn care: a feasibility assessment. Bull. World Health Organ. 95, 445-452I. https://doi.org/10.2471/BLT.16.179531

Madan, Panchal, V., Shringarpure, K.( 2012). Effect of Antenatal Counseling on Initiation of Breastfeeding - An Interventional Study. Indian J. Matern. Child Health 14, 1-7.

Mukhtar Yola, M., Audu, L.I., Olaniyan, O., Akinbi, H.T., Dawodu, A., Donovan, E.F., (2018). Decreasing Birth Asphyxia: Utility of Statistical Process Control in a LowResource Setting. BMJ Open Qual. 7. https://doi.org/10.1136/bmjoq-2017-000231

Nimi, T., Fraga, S., Costa, D., Campos, P., Barros, H. (2016). Prenatal care and pregnancy outcomes: A cross-sectional study in Luanda, Angola. Int. J. Gynaecol. Obstet. Off. Organ Int. Fed. Gynaecol. Obstet. 135 Suppl 1, S72-S78. https://doi.org/10.1016/j.ijgo.2016.08.013

Pemprov Jawa Tengah. (2018). Student Osoc Tak Harus Mahasiswa. URL https://jatengprov.go.id/publik/student-osoc-tak-harus-mahasiswa/ (accessed 12.2.19).

Riskesdas. (2013). Hasil Riskesdas 2013_2(Autosaved).pdf.

Rode, S. (2018). Effect of Complete Antenatal Care on Birth Weight of Children in India: Evidence from National Family Health Survey (NFHS) Data. J. Women's Health Care 07. https://doi.org/10.4172/2167-0420.1000412

Sandall, J., Soltani, H., Gates, S., Shennan, A., Devane, D. (2016). Midwife-led continuity models versus other models of care for childbearing women. Cochrane Database Syst. Rev. 4, CD004667. https://doi.org/10.1002/14651858.CD004667.pub5

Sauls, D. (2002). Effects of Labor Support on Mothers, Babies, and Birth Outcomes. Jognn 31, 733-741. https://doi.org/10.1177/088421702129005380 
Sehhaty, F., Najarzadeh, M., Zamanzadeh, V., Seyyedrasooli, A. (2014). The Effect of Midwifery Continuing Care on Childbirth Outcomes. Iran. J. Nurs. Midwifery Res. 19, 233-237. https://doi.org/Doi: 10.12669/pjms.323.9546

Shimoda, K., Leshabari, S., Horiuchi, S., Shimpuku, Y., Tashiro, J. (2015). Midwives' intrapartum monitoring process and management resulting in emergency referrals in Tanzania: a qualitative study. BMC Pregnancy Childbirth 15, 248. https://doi.org/10.1186/s12884-015-0691-0

Sydsjo, G., Blomberg, M., Palmquist, S., Angerbjörn, L., Bladh, M., Josefsson, A. (2015). Effects of Continuous Midwifery Labour Support for Women with Severe Fear of Childbirth. BMC Pregnancy Childbirth 15. https://doi.org/10.1186/s12884-015-0548-6

Takahashi, K., Ganchimeg, T., Ota, E., Vogel, J.P., Souza, J.P., Laopaiboon, M., Castro, C.P., Jayaratne, K., Ortiz-Panozo, E., Lumbiganon, P., Mori, R.(2017). Prevalence of Early Initiation of Breastfeeding and Determinants of Delayed Initiation of Breastfeeding: Secondary Analysis of the Who Global Survey. Sci. Rep. 7. https://doi.org/10.1038/srep44868

Thompson, J.F., Heal, L.J., Roberts, C.L., Ellwood, D.A. (2010). Women's breastfeeding experiences following a significant primary postpartum haemorrhage: A multicentre cohort study. Int. Breastfeed. J. 5, 5. https://doi.org/10.1186/1746-4358-5-5

UNICEF.(2017). Maternal mortality [WWW Document]. UNICEF DATA. URL https://data.unicef.org/topic/maternal-health/maternal-mortality/ (accessed 4.4.19).

UNICEF and WHO. (2003). Antenatal Care in Developing Countries Promises, achievements and missed opportunities. An analysis of trends, levels and differentials, 1990-2001. Publication date: 2003.

United Nations Children's Fund, (2017). Maternal mortality [WWW Document]. UNICEF DATA. URL https://data.unicef.org/topic/maternal-health/maternal-mortality/ (accessed 4.18.19).

WHO.(2018). Who Recommendation on Continuity of Care for a Positive Childbirth \begin{tabular}{l|lll} 
Experience & Rhl & [WWW & Document]. URL
\end{tabular} https://extranet.who.int/rhl/topics/preconception-pregnancy-childbirth-and-postpartumcare/care-during-childbirth/who-recommendation-continuity-care-positive-childbirthexperience (accessed 4.2.19).

WHO. (2013). More midwives needed to improve maternal and newborn survival. Bull. World Health Organ. 91, 804-805. https://doi.org/10.2471/BLT.13.021113

WHO. (2011). Newborn Death and Illness [WWW Document]. WHO. URL https://www.who.int/pmnch/media/press_materials/fs/fs_newborndealth_illness/en/ (accessed 4.7.20).

WHO. (2006). who_New borns Low Birth Weight.pdf [WWW Document]. URL https://www.who.int/whosis/whostat2006NewbornsLowBirthWeight.pdf

WHO, USAID, MCHIP, MCSP.(2015). Postnatal Care for Mothers and Newborns Highlights from the World Health Organization 2013 Guidelines.

WHO. (2018). Maternal Mortality [WWW Document]. Matern. Mortal. URL https://www.who.int/news-room/fact-sheets/detail/maternal-mortality (accessed 4.2.19).

WHO. (2017). World health statistics 2017: monitoring health for the SDGs, Sustainable Development Goals. World Health Organization, Genève.

WHO (Ed.). (2016). Who Recommendations on Antenatal Care for a Positive Pregnancy Experience. World Health Organization, Geneva.

Yuningsih, R. (2016). Pengembangan Kebijakan Profesi Bidan dalam Upaya Meningkatkan Pelayanan Kesehatan Ibu dan Anak. J. Aspir. 7, 63-76-76. https://doi.org/10.22212/aspirasi.v7i1.1280. 